\title{
ARQUITETURA SUSTENTÁVEL NO ESPAÇO URBANO
}

Camila Message Silva' ${ }^{1}$ Jéssica Telles Zanateli', Mayara Pissutti Albano² ${ }^{2}$ Yeda Ruiz Maria²

${ }^{1}$ Discentes do curso de Arquitetura e Urbanismo da Universidade do Oeste Paulista - UNOESTE. ${ }^{2}$ Docente dos cursos de arquitetura e urbanismo, design de interiores, engenharia ambiental sanitária e engenharia de produção da Universidade do Oeste Paulista - UNOESTE. Email: jessicazanateli@yahoo.com.br

\section{RESUMO}

Atualmente existem vários conceitos para o termo sustentabilidade. Em suma, a palavra representa a gestão dos recursos sem desperdício e nem danos ao meio, de maneira a garantir o sustento da geração presente e das futuras. Entretanto a dificuldade de adaptação se deve ao hábito geral da população de não se preocupar com o uso e preservação dos recursos naturais. $A$ ideia de desenvolvimento sustentável compreende esfera bem maior do que apenas a questão ambiental, abrangendo também a arquitetura, trazendo a inserção das práticas de sustentabilidade ao setor construtivo, proporcionando qualidade, vantagens e soluções na concepção do projeto, manutenção e mesmo na maneira de lidar com resíduos de demolição, e também no âmbito das cidades, utilizado a sustentabilidade como forma de inserir atividades e políticas públicas no planejamento urbano.

Palavras-chave: Sustentabilidade, Recursos Naturais, Impactos Ambientais, Arquitetura, Planejamento Urbano.

\section{INTRODUÇÃO}

Os seres humanos são considerados racionais e por conta disso, acreditam ter direitos sobre os outros seres e tratando os recursos naturais como infinitos (CANEPA, 2007; LEITE, 2011). Para Valentim, Kroetz e Toigo (2012) as pessoas se mostram resistentes a poupar e preservar 0 que a natureza oferece, por isso em pleno século XXI assiste-se às mudanças naturais dos mais diversos níveis decorrentes da ação humana no meio ambiente. A crise ambiental exige cada vez mais soluções que diminuam o impacto do homem sobre a natureza. Neste contexto, surge a iminente preocupação da escassez dos recursos naturais, demandando assim, a busca por saídas aceitáveis tanto para o uso dos recursos naturais bem como para a destinação de seus resíduos (VALENTIM, KROETZ e TOIGO, 2012).

De acordo com Cavalcanti (2013) o termo sustentável é utilizado para todo o processo que oferece continuidade e preservação dos recursos com qualidade. Na prática é toda atividade humana que não acaba com os recursos naturais de seu ambiente, proporcionando-Ihe tempo e condições para que seja renovado por meios naturais ou por ações humanas. Cavalcanti (2013) confirma que a arquitetura visa melhorar a qualidade de vida humana, seus princípios precisam ser utilizados para fazer das áreas florestais mais confortáveis e evitar sua destruição para dar 
espaço à construção de ambientes urbanos. É uma atividade que implica de imediato no quesito básico da sustentabilidade: o planejamento. Aplicado desde a escolha do terreno no projeto arquitetônico e no processo de construção, o planejamento pode carregar a sustentabilidade sem interferir negativamente na realização e no conceito do projeto. Outra questão de extrema importância e que deve ser inserida na elaboração do edifício é o tratamento adequado às águas da chuva, incluindo a captação, tratamento e armazenamento para a reutilização da mesma em determinadas instalações. A arquitetura com preocupações sustentáveis está se mostrando importante e vantajosa, visando o bem estar de seus usuários assim como o desperdício dos recursos e o gasto com o uso deles (CAVALCANTI, 2013).

A sustentabilidade não se envolve apenas com a arquitetura, mas principalmente com o planejamento urbano, buscando através deste, relacionar o desenvolvimento sustentável às cidades. Nesta linha de pensamento Sampaio (2009) diz que de acordo com Schussel (2004) a sustentabilidade urbana deve ter um perfil pluridimensional, favorecendo o acesso, estabelecendo uma união entre todas as pessoas e o meio ambiente natural, e promovendo a manutenção do patrimônio histórico e cultural.

Nesse contexto o objetivo principal deste artigo é demonstrar a possibilidade e a importância de usar adequadamente os recursos naturais e de praticar a sustentabilidade principalmente no meio arquitetônico, de estabelecer uma relação entre o desenvolvimento sustentável e o meio urbano. Especificamente tem-se como objetivo analisar a Casa Eficiente e traçar um perfil arquitetônico sustentável.

A metodologia do presente trabalho compreende a busca por informações de profissionais conhecedores de assuntos relacionados ao meio ambiente e a consulta de livros e artigos da internet sobre o tema, pincipalmente sobre A Casa Eficiente, modelo de eficiência em desempenho térmico.

\section{SUSTENTABILIDADE NA ARQUITETURA}

De acordo com o relatório de Brundtland (1987) sustentabilidade é o desenvolvimento que atende as necessidades das gerações atuais sem comprometer a capacidade das futuras gerações terem suas próprias necessidades atendidas. Sendo a arquitetura, entre vários outros conceitos, uma intervenção no meio, deve estar unida à sustentabilidade para reduzir danos e garantir a oferta de recursos. 
Em 1992 é realizada no Rio de Janeiro a Conferência das Nações Unidas sobre o Meio Ambiente e Desenvolvimento (Eco'92 ou Rio'92), no qual nasce a Agenda 21, um programa de ação e não apenas de constatação, que fala de cooperação internacional para acelerar o desenvolvimento sustentável; promoção da conscientização ambiental (SZABO, 2005). Houve um pronunciamento no congresso de Chicago entre os arquitetos sobre a questão da sustentabilidade, onde os arquitetos propuseram um termo de compromisso para a produção de projetos sustentáveis, responsáveis frente aos recursos, eficientes sob o aspecto energético, ecológico e social, gerando edificações que oferecem acima da estética, baixo impacto ambiental e produzam um novo paradigma de projetos arquitetônicos. O crescimento acelerado das cidades tem causado uma queda na qualidade de vida e consequentemente um crescimento dos problemas sociais e ambientais, mostrando a importância de políticas públicas e privadas que levem consigo princípios de sustentabilidade (AGENDA 21, 1992).

Do exposto entende-se que no final da década de 1980 e início da década de 1990 as questões de sustentabilidade chegaram de forma incisiva, trazendo novos paradigmas e uma revolução no modo de pensar o projeto e a forma de construção. É importante a mobilização dos habitantes e construtores em contribuir com a redução dos impactos na cidade, buscando através do uso adequado dos recursos naturais, em habitações, edifícios, planos urbanos, uma cidade sustentável.

Com relação à arquitetura Szabo (2005) coloca que é necessária a elaboração de projetos utilizando-se de estratégias que levam em consideração o meio ambiente e a cultura local. Assim propõe que os princípios desse novo paradigma projetual devem evitar danos ao meio ambiente, considerando o ar, a água, o solo, a flora, a fauna, e o ecossistema; avaliar o impacto sobre o meio em toda e qualquer decisão; preservar a herança e diversidade cultural; selecionar matérias atóxicas, recicláveis e reutilizáveis; promover eficiência energética com ênfase em fontes alternativas; valorizar a inteligência nas edificações para aperfeiçoar o uso, incentivar o transporte coletivo e alternativo; projetar pensando em todo ciclo de vida da edificação, incluindo, portanto sua reciclagem ou demolição. De acordo com Kronka (2002) a principal tarefa dos profissionais ligados à construção neste momento, onde a ação do homem na natureza tornou-se insustentável, reside não só nos aspectos funcionais, bioclimáticos e operacionais das edificações, mas principalmente no desafio de implantar novo modo de vida cabendo aos profissionais contribuições não só quanto aos aspectos ambientais, mas principalmente quanto aos sociais, pois esta "nova arquitetura" só será viável com base em novos paradigmas. 
Sendo assim, a arquitetura sustentável busca difundir novas maneiras construtivas que minimizem os impactos ambientais, para maiores ganhos tanto econômicos, quanto sociais e ambientais. Embora seja uma prática vantajosa ainda é vista como um diferencial, mas no futuro vai fazer uma enorme diferença e certamente se tornará uma necessidade.

\section{ESTUDO DE CASO: CASA EFICIENTE - LABEEE}

Devido à temática abordada no artigo, as referências arquitetônicas são muito importantes como comprovantes da teoria elaborada, sendo referenciais de aspectos positivos e negativos da pesquisa.

A Casa Eficiente, elaborada pelo Laboratório de Eficiência Energética em Edificações LABEEE da Universidade Federal de Santa Catarina é um importante referencial para a exemplificação de arquitetura sustentável abordada no presente artigo, devido a toda sua estrutura embasada em preocupações com a eficiência energética, uso adequado dos recursos naturais e suas possibilidades sustentáveis tanto em aspectos econômicos, sociais e de conforto ao ambiente. Seu projeto arquitetônico foi concebido pelas arquitetas Alexandra Maciel e Suely Andrade junto com a colaboração de pesquisadores do Labeee, da UFSC e através deste, a execução resultou da parceria estabelecida entre a ELETROSUL, ELETROBRAS/PROCEL Edifica e a Universidade Federal de Santa Catarina (UFSC) (LAMBERTS et al, 2010).

A casa foi projetada com as características climáticas da região, baseada na NBR 15220; 2005, onde se insere e funciona como centro de pesquisa, onde são monitoradas as diferentes tecnologias utilizadas. O grande destaque da casa é a geração de energia elétrica através de um sistema fotovoltaico conectado à rede e instalado na cobertura central da casa. O painel foi instalado de acordo com a inclinação de Florianópolis (270 de latitude) de forma a obter o seu máximo rendimento. Durante um período de dois anos a casa funcionou em duas etapas, a primeira foi como um laboratório de pesquisas para doutorados, mestrados e iniciações científicas e a segunda como um centro de visitações ao público, sendo inaugurado em 29 de março de 2006 (LAMBERTS et al, 2010).

Diante de toda a análise vista da casa eficiente, conclui-se que a casa produziu durante este tempo de pesquisa e monitoramentos, estratégias bioclimáticas baseadas em dados reais que produziram resultados eficazes, para um melhor conforto do ambiente e também gerou economias energéticas. Porém, também serviu para solucionar problemas do projeto, tendo assim que efetuar mudanças, servindo como um perfeito objeto de estudo. 


\section{CONSIDERAÇÕES FINAIS}

Este artigo evidencia, diante de todas as fundamentações teóricas, a importância da sustentabilidade dentro da arquitetura com a necessidade de se preservar os recursos naturais e também aplicá-los de forma adequada na construção civil, evitando desperdícios e garantindo maior prazo para renovação dos mesmos pela natureza e ao passo que assegura a existência deles para as futuras gerações. A construção sustentável contribui com a promoção do desenvolvimento sustentável através de políticas públicas na cidade e também com a integração do meio natural equilibrando-se com o acelerado crescimento do cotidiano no meio urbano.

As práticas sustentáveis envolvem o social, o ambiental e o econômico, um resultado justo dentro da sociedade, sendo ambientalmente correto, economicamente viável e culturalmente aceito. Aceito ao ponto de causar uma mudança no cotidiano das pessoas para o bem delas e do meio.

\section{REFERÊNCIAS}

AGENDA 21. Programme of action for sustainable development. New York: United Nations, 1992.

BRUNDTLAND, Gro Harlem. Our common future: The World Commission on Environment and Development. Oxford: Oxford University, 1987.

CANEPA, Carla - Cidades Sustentáveis: O Município como Locus da Sustentabilidade. São Paulo: RCS Editora, 2007.

CAVALCANTI, Lorena. Arquitetura sustentável - o que é um projeto sustentável? Disponível para download em <http://www.sustentabilidades.com.br/index.php?Option =com content

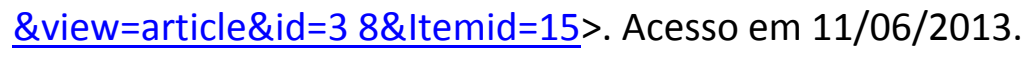

KRONKA, Roberta C. Mülfarth - Arquitetura de Baixo Impacto Humano e Ambiental. Tese de doutorado. FAU-USP. São Paulo, dezembro 2002.

LAMBERTS, Roberto; GHISI, Enedir; PEREIRA, Cláudia Donald; BATISTA, Juliana Oliveira. CASA EFICIENTE: Bioclimatologia e Desempenho Térmico. Florianópolis: UFSC (Universidade Federal de Santa Catarina), 2010.

LEITE, Luis Gustavo Tirado - Desenvolvimento Sustentável Ambiental: Parceria Público privada Alternativa na Gestão de Resíduos Sólidos Urbanos. Dissertação apresentada ao Programa de Mestrado em Direito da Universidade de Marília, área de concentração Empreendimentos Econômicos, Desenvolvimento e Mudança Socia. Marília, 2011. Disponível para download em <http://www.unimar.br/pos/trabalhos/arquivos/190CB3FBFED660C43585644358615652.pdf>. Acesso em 11/06/2013. 
MARCONI, Marina de Andrade; LAKATOS, Eva Maria. Técnicas de Pesquisa: Planejamentos e execuções de pesquisas, amostragens e técnicas de pesquisa, elaboração, análise e interpretações de dados. 6ạ. Ed. São Paulo: Atlas, 2006.

PEDIGRER, P. W. Avaliação do Grau de Sustentabilidade de um Condomínio Residencial- Estudo de Caso. 2008. Trabalho de Conclusão de Curso (Graduação em Engenharia Civil) - Universidade Regional do Noroeste do Estado do Rio Grande do Sul, ljuí, 2008.

SAMPAIO, Danusa Teodoro - Sustentabilidade Urbana: Conceitos e Controvérsias. Disponível para download em <http://www.elecs2013.ufpr.br/wp content/uploads/anais /2009/2009 artigo 187.PDF>. Acesso em 07/06/2013.

SZABO, Ladislao; GUERRA, Abilio; RUSSO, Filomena. Iniciativa Solvin 2005: Arquitetura Sustentável. São Paulo: Romano Guerra Editora, 2005.

VALENTIM, Hilda; FAVERI, Dinora; KROETZ, Marilei; TOIGO, Renata - Responsabilidade Socioambiental pele Consumo Consciente. Disponível para download em <http://www.aedb.br/seget/artigos12/56016670.pdf>. Acesso em 11/06/2013. 